\title{
Assesment of Frequency-Magnitude of Extreme Rainfall Events-Case Study of the MeKong River Delta
}

\author{
Pham Hai An ${ }^{1}$, Tran Anh Tu ${ }^{1}$, Tran Dinh Lan ${ }^{1}$ and Nguyen Ngoc Tien ${ }^{2}$ \\ 1. Institute of Marine Environment and Resources, VAST, Haiphong 180000, Vietnam \\ 2. Institute of Marine Geology and Geophysics, VAST, Hainoi 1000000, Vietnam
}

\begin{abstract}
Extreme rainfall events are primary natural hazards, which cause a severe threat to people and their properties in populated cities, which are normally located in coastal areas in Vietnam. Analysing these events by using a data series observed over years will support us to draw a picture of how the climate change impact on local environments. The purpose of this report is to understand the characteristics of the extreme rainfall events in MEKONG river delta (south VietNam). Daily rainfall data in the period of 30 years for a meteorological station in each area were collected from the Vietnam National Hydro-meteorological Service. The extreme rainfall events were defined as those exceeding the 95th percentile for each station. The analytical results show that the rainfall values (95th percentile) are $37.4 \mathrm{~mm} /$ day at Nam Can station, $27 \mathrm{~mm} /$ day at My Thanh station, $22.4 \mathrm{~mm} / \mathrm{day}$ at Hoa Binh station, $23.8 \mathrm{~mm} /$ day at Binh Dai station and $22.7 \mathrm{~mm} /$ day at Ben Trai station. The highest rainfall data ever recorded are 246.4 mm/day (Nam Can), 174.5 mm/day (My Thanh), 179 mm/day (Hoa Binh), 187.3 mm/day (Binh Dai) and 136.3 mm/day (Ben Trai) during 1983-2012. The result of the Mann-Kendall tests show that there was a significant creasing of the rainfall at Nam Can, My Thanh station in two periods (1983-2012, 1998-2012) while no clear trend of the rainfall was recoreded at Hoa Binh, Binh Dai, Ben Trai station. In order to estimate the return period of the extreme rainfall events, the method General Extreme Value Distribution was used to calculate frequent distribution. The magnitudes of daily maximum rainfall were from 2 to 100 years. The results of return period show that maximum rainfalls are $46.6 \mathrm{~mm}$ at Nam Can station (highest) and $31.4 \mathrm{~mm}$ at Hoa Binh station (lowest) during 50 years. Similarly, maximum rainfalls are expected to be about $55.1 \mathrm{~mm}$ at Nam Can station and $37.2 \mathrm{~mm}$ at Hoa Binh station for 100 years.
\end{abstract}

Key words: Generalized extreme value distribution, MEKONG river delta.

\section{Introduction}

In recent years, weather and climate tend complicated. The vagaries of weather and climate have a significant impact on the variability of meteorological factors, especially precipitation. The transformation of rainfall will affect the hydrological cycle and water resources in the climate system, leading to alter the mean values of temperature and precipitation, which increases the volatility of the phenomenon of rain strengthening or weakening causing floods or drought, especially for the MEKONG river delta region.

MEKONG river delta region has the tropical climate, hot and humid, influenced by monsoon

Corresponding author: Pham Hai An, master, research field: physical oceanography. E-mail: anph@imer.ac.vn. comprehensively. Each year there are two main seasons: rainy and dry season. Every year, there is considerable precipitation, average 1,400-2,200 $\mathrm{mm} /$ year. The months with rainy days are at least from December to March, varying from 0 to 8 rainy days/month. The months with the highest rainfall days are from May to October, varying from 15 to 21 rainy days/month. Precipitation is about from 78 to $92 \%$ in the rainy season.

Compared to other regions in the country, the rainfall in the study area has been changed little. But the remarkable matter is that the region has 2 rainy peaks: the first rainy peak in June, July; the second rainy peak in September, October 10. Between two rainy peak, from late July to early August, there has a short dry period lasting approximately 10 days due to 
the effects of antycyclone gust of winds on the high layer.

In this area, there are the biggest threats including the increasingly frequencies and more intense extreme climate events such as heavy rainfall events. In order to clearly understand the extreme rainfall characteristics and their associated consequences in MeKong river delta, daily rainfall data have been collected and analyzed for 30 years.

\section{Material and Methods}

Daily rainfall data recorded at 5 Meteorological Stations in MEKONG river delta for the period 1983-2012 (NamCan-S1, MyThanh-S2, HoaBinh-S3, BinhDai-S4, BenTrai-S5), they were collected from the Vietnam National Hydro-meteorological Service.

Recent studies indicate that the most useful method for detecting the trend was the non-parametric Mann-Kendall trend test. Mann (1945) originally found the test and then after Kendall (1975) developed and completed the test, which was known as the Kendall's tau statistic [1,2]. This was the excellent tool for trend detection in different applications [3-5].

Under the null hypothesis $\mathrm{H}_{0}$, a series $\left\{\mathrm{x}_{1}, \ldots, \mathrm{x}_{\mathrm{N}}\right\}$ comes from a population where the random variables are independent and identically distributed (i.e. the null hypothesis is of no trend) the Mann-Kendall test statistic is:

$$
\begin{gathered}
S=\sum_{i=1}^{N-1} \sum_{j=i+1}^{N} \operatorname{sign}\left(x_{\mathrm{j}}-x_{\mathrm{i}}\right) \\
\operatorname{sign}(x)=1 \text { if } x>0 \\
\operatorname{sign}(x)=0 \text { if } x=0 \\
\operatorname{sign}(x)=-1 \text { if } x<0
\end{gathered}
$$

A very high positive value of $S$ is an indicator of an increasing trend, and a very low negative value indicates a decreasing trend. However, it is necessary to compute the probability associated, with $\mathrm{S}$ and the sample size, $\mathrm{n}$, to statistically quantify the significance of the trend. As such, $\mathrm{S}$ is calculated by using the above formula. The calculation of the variance of $S$, $\operatorname{VAR}(\mathrm{S})$, is made by applying the following Eq. (2):

$$
\operatorname{VAR}(S)=\frac{1}{8}[n(n-1)(2 n+5)-T]
$$

$$
T=\sum_{p=1}^{g} t_{p}\left(t_{p}-1\right)\left(2 t_{p}+5\right)
$$

Where, $\mathrm{n}$ is the number of data points, $\mathrm{g}$ is the number of tied groups (a tied group is a set of sample data having the same value), and $p t$ is the number of data points in the pth group. In the sequence $\{2,3$, non-detect, 3 , non-detect, 3$\}, \mathrm{n}=6, \mathrm{~g}=2, \mathrm{t}_{1}=2$ for the non-detects, and $t_{2}=3$ for the tied value 3 . Compution of a normalized test statistic $\mathrm{Z}$ is made as:

$$
\begin{aligned}
& Z=\frac{S-1}{[\operatorname{VAR}(S)]^{1 / 2}}, S>0 \\
& Z=0, S=0 \\
& Z=\frac{S+1}{[\operatorname{VAR}(S)]^{1 / 2}}, S<0
\end{aligned}
$$

Then, it is needed to compute the probability associated with this normalized test statistic. The probability density function for a normal distribution with a mean of 0 and a standard deviation of 1 is given by the following Eq. (4):

$$
f(z)=\frac{1}{\sqrt{2 \pi}} e^{-\frac{z^{2}}{2}}
$$

The trend is said to be decreasing if $\mathrm{Z}$ is negative and the computed probability is greater than the level of significance. The trend is said to be increasing if the $\mathrm{Z}$ is positive and the computed probability is greater than the level of significance. If the computed probability is less than the level of significance, there is no trend. To find the amount of increase or decrease in 30 years, the authors have adopted the least square linear fit of the data. Advantage of linear regression is that it provides an estimate of slope, confidence interval, and quantifies goodness of fit.

However, it does not handle missing data and may be greatly affected by outliers and cyclic data. As mentioned earlier in our case, the authors have removed the effect of missing days' observation by dividing the actual annual frequency with actual number of observation of that year and then multiplying by the number of days of that year. To 
determine the extreme rainfall values for 5, 10, 25, 50 and 100 years, the return periods are calculated. Probabilistic extreme value theory, which primarily deals with the stochastic behavior of the maximum and minimum random variables, extreme and intermediate order statistics and exceedance over (below) high (low) thresholds are determined by the underlying distribution.

Traditionally, the three extreme value distributions are applied to annual maximum daily rainfall. In this study, the authors have used the generalized extreme value (GEV) distribution, which has all the flexibility of all the other extreme value distributions. The GEV distribution was developed by Jenkinson [6], Hosking et al. [7] and Galambos [8]. The cumulative distribution function (CDF) of the GEV distribution is:

$$
F(x, \psi, \beta)=\exp \left(-1\left(1+\zeta \frac{x-\psi}{\beta}\right)^{-1 / \zeta}\right)
$$

For $1+\xi(\mathrm{x}-\psi) / \beta>0$, where $\psi, \beta$ and $\xi$ are referred to as the location, scale and shape parameters respectively. The particular case of (1) for $\xi>0$ is the Gumbel distribution:

$$
F(x, \psi, \beta)=\exp (-\exp ((\psi-x) / \beta))
$$

The median is:

$$
\psi-\beta \ln (-\ln (1 / 2))
$$

The mean is $\psi+\gamma \beta$ where $\gamma$ - EulerMascheroni constan $\approx 0.577215665$. The standard deviation is $\beta \pi / 61 / 2$. The mode is $\psi$.Then from the Gumbel distribution with parameters $\psi$ and $\beta$, the extreme value (return value) $\mathrm{x}$ for a period of $\mathrm{n}$ years can be written by the following formula: $x=\psi-\beta \ln [-\ln (F)]$. Note: $\psi=$ average $-\gamma \beta$ (where $\gamma$ is Euler's constant, approximately 0.557 ), and $\beta=0.78 \sigma$, with $\sigma$ is the standard deviation. $\mathrm{F}$ is the random variety drawn from the uniform distribution in the interval $[0,1]=$ $(\mathrm{N}-1) / \mathrm{N}$.

\section{Results}

\subsection{Trend Analysis}

MEKONG river delta: The data analytical results show that the monthly rainfalls vary from $3 \mathrm{~mm}$ to $408 \mathrm{~mm}$ within 30 years. Monthly average rainfall is at peaks in rainy season (months from May to October), and very low in other seasons, less than 100 mm (Fig. 1). Annual total rainfall in MeKong river delta are various from $110.5 \mathrm{~mm}$ to $2,963.8 \mathrm{~mm}$ (Fig. 2). Besides, the characteristic statistics of data in 30 years at 5 stations was shown in Tables 1-15. The measured data was divided into three different periods, each period was examined by the Mann-Kendall trend test (the first 1983-2012: Period-1, the second 1983-1997: Period-2, the third: 1998-2012: Period-3).

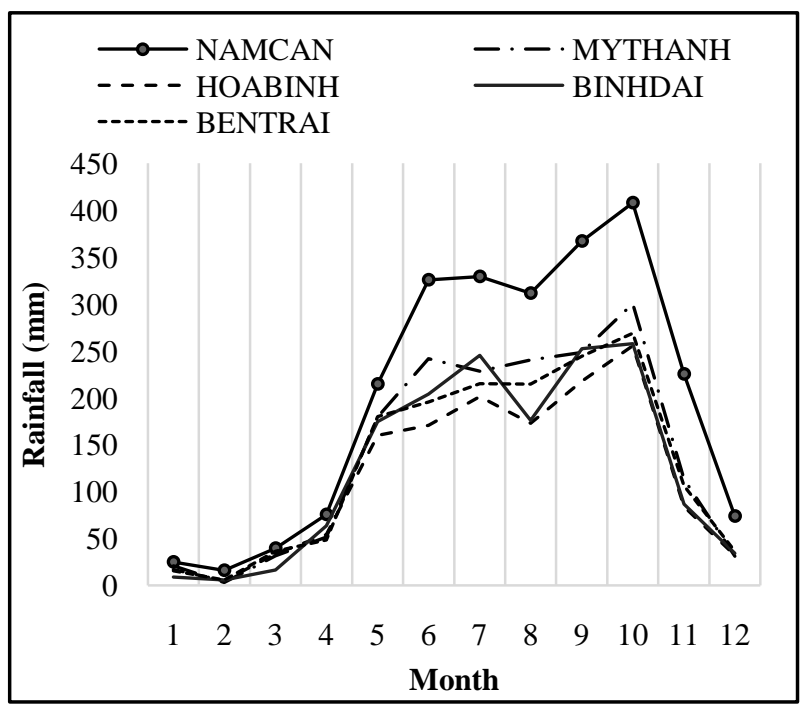

Fig. 1 Monthly mean rainfall $(\mathrm{mm})$ at 5 station in MEKONG river delta.

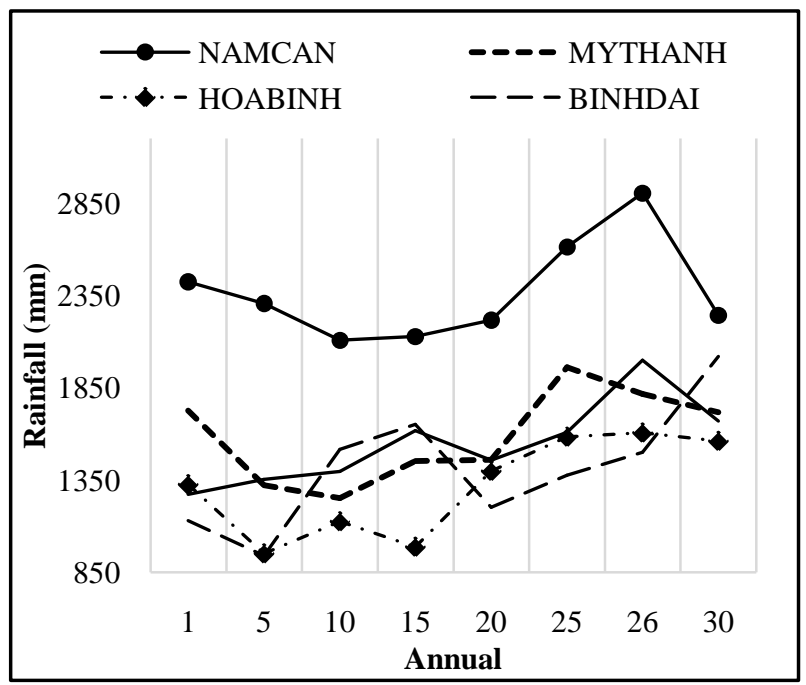

Fig. 2 Annual rainfall $(\mathrm{mm})$ at 5 station in MEKONG river delta (1983-2012). 
Table 1 Descriptive statistics of data recorded at Nam Can station (S1).

\begin{tabular}{llll}
\hline Statistic Period-1 & Value & Percentile & Value \\
\hline Sample size & 10,950 & Min & 0 \\
Range & 246.4 & $5 \%$ & 0 \\
Mean & 6.424 & $10 \%$ & 0 \\
Variance & 240.1 & $25 \%$ Q1 & 0 \\
Std. deviation & 15.5 & $50 \%$ Median & 0 \\
Coef. of variation & 2.412 & $75 \%$ Q3 & 4.5 \\
Std. error & 0.148 & $90 \%$ & 23.19 \\
Skewness & 4.197 & $95 \%$ & 37.445 \\
Excess kurtosis & 26.99 & Max & 246.4 \\
\hline
\end{tabular}

* Period 1: 1983-2012.

Table 2 Descriptive statistics of data recorded at Nam Can station (S1).

\begin{tabular}{llll}
\hline Statistic Period-2 & Value & Percentile & Value \\
\hline Sample size & 5,475 & Min & 0 \\
Range & 246.4 & $5 \%$ & 0 \\
Mean & 5.975 & $10 \%$ & 0 \\
Variance & 232.5 & $25 \% \mathrm{Q} 1$ & 0 \\
Std. deviation & 15.25 & $50 \%$ Median & 0 \\
Coef. of variation & 2.552 & $75 \%$ Q3 & 3.2 \\
Std. error & 0.206 & $90 \%$ & 21.9 \\
Skewness & 4.611 & $95 \%$ & 35.6 \\
Excess kurtosis & 33.33 & Max & 246.4 \\
\hline
\end{tabular}

* Period 2: 1983-1997.

Table 3 Descriptive statistics of data recorded at Nam Can station (S1).

\begin{tabular}{llll}
\hline Statistic Period-3 & Value & Percentile & Value \\
\hline Sample size & 5,475 & Min & 0 \\
Range & 218 & $5 \%$ & 0 \\
Mean & 6.874 & $10 \%$ & 0 \\
Variance & 247.5 & $25 \%$ Q1 & 0 \\
Std. deviation & 15.73 & $50 \%$ Median & 0 \\
Coef. of variation & 2.288 & $75 \%$ Q3 & 5.8 \\
Std. error & 0.212 & $90 \%$ & 24 \\
Skewness & 3.824 & $95 \%$ & 39.4 \\
Excess kurtosis & 21.49 & Max & 218 \\
\hline
\end{tabular}

* Period 3: 1998-2012.
Table 4 Descriptive statistics of data recorded at My Thanh station (S2).

\begin{tabular}{llll}
\hline Statistic Period-1 & Value & Percentile & Value \\
\hline Sample size & 10,950 & Min & 0 \\
Range & 174.5 & $5 \%$ & 0 \\
Mean & 4.374 & $10 \%$ & 0 \\
Variance & 139.4 & $25 \%$ Q1 & 0 \\
Std. deviation & 11.81 & $50 \%$ Median & 0 \\
Coef. of variation & 2.699 & $75 \%$ Q3 & 1.8 \\
Std. error & 0.1134 & $90 \%$ & 14.5 \\
Skewness & 4.716 & $95 \%$ & 27 \\
Excess kurtosis & 32.36 & Max & 174.5 \\
\hline
\end{tabular}

* Period 1: 1983-2012.

Table 5 Descriptive statistics of data recorded at My Thanh station (S2).

\begin{tabular}{llll}
\hline Statistic Period-2 & Value & Percentile & Value \\
\hline Sample size & 5,475 & Min & 0 \\
Range & 144.3 & $5 \%$ & 0 \\
Mean & 4.137 & $10 \%$ & 0 \\
Variance & 133.4 & $25 \%$ Q1 & 0 \\
Std. deviation & 11.55 & $50 \%$ Median & 0 \\
Coef. of variation & 2.792 & $75 \%$ Q3 & 0.3 \\
Std. error & 0.156 & $90 \%$ & 13.64 \\
Skewness & 4.425 & $95 \%$ & 26.42 \\
Excess kurtosis & 25.84 & Max & 144.3 \\
\hline
\end{tabular}

* Period 2: 1983-1997.

Table 6 Descriptive statistics of data recorded at My Thanh station (S2).

\begin{tabular}{llll}
\hline Statistic Period-3 & Value & Percentile & Value \\
\hline Sample size & 5,475 & Min & 0 \\
Range & 174.5 & $5 \%$ & 0 \\
Mean & 4.611 & $10 \%$ & 0 \\
Variance & 145.4 & $25 \%$ Q1 & 0 \\
Std. deviation & 12.06 & $50 \%$ Median & 0 \\
Coef. of variation & 2.615 & $75 \%$ Q3 & 2.8 \\
Std. error & 0.164 & $90 \%$ & 15.3 \\
Skewness & 4.967 & $95 \%$ & 27.22 \\
Excess kurtosis & 37.72 & Max & 174.5 \\
\hline
\end{tabular}

* Period 3: 1998-2012. 
Table 7 Descriptive statistics of data recorded at Hoa Binh station (S3).

\begin{tabular}{llll}
\hline Statistic Period-1 & Value & Percentile & Value \\
\hline Sample size & 10,950 & Min & 0 \\
Range & 179 & $5 \%$ & 0 \\
Mean & 3.671 & $10 \%$ & 0 \\
Variance & 114.1 & $25 \%$ Q1 & 0 \\
Std. deviation & 10.68 & $50 \%$ Median & 0 \\
Coef. of variation & 2.91 & $75 \%$ Q3 & 0.1 \\
Std. Error & 0.102 & $90 \%$ & 11.5 \\
Skewness & 5.11 & $95 \%$ & 22.445 \\
Excess kurtosis & 37.92 & Max & 179 \\
\hline
\end{tabular}

* Period 1: 1983-2012.

Table 8 Descriptive statistics of data recorded at Hoa Binh station (S3).

\begin{tabular}{llll}
\hline Statistic Period-2 & Value & Percentile & Value \\
\hline Sample size & 5,475 & Min & 0 \\
Range & 130.3 & $5 \%$ & 0 \\
Mean & 3.344 & $10 \%$ & 0 \\
Variance & 98 & $25 \%$ Q1 & 0 \\
Std. deviation & 9.899 & $50 \%$ Median & 0 \\
Coef. of variation & 2.961 & $75 \%$ Q3 & 0 \\
Std. error & 0.134 & $90 \%$ & 10.6 \\
Skewness & 5.257 & $95 \%$ & 20.3 \\
Excess kurtosis & 38.16 & Max & 130.3 \\
\hline
\end{tabular}

* Period 2: 1983-1997.

Table 9 Descriptive statistics of data recorded at Hoa Binh station (S3).

\begin{tabular}{llll}
\hline Statistic Period-3 & Value & Percentile & Value \\
\hline Sample size & 5,475 & Min & 0 \\
Range & 179 & $5 \%$ & 0 \\
Mean & 3.998 & $10 \%$ & 0 \\
Variance & 130.1 & $25 \%$ Q1 & 0 \\
Std. deviation & 11.41 & $50 \%$ Median & 0 \\
Coef. of variation & 2.853 & $75 \%$ Q3 & 0.4 \\
Std. error & 0.154 & $90 \%$ & 12.7 \\
Skewness & 4.943 & $95 \%$ & 24.94 \\
Excess kurtosis & 36.51 & Max & 179 \\
\hline
\end{tabular}

* Period 3: 1998-2012.
Table 10 Descriptive statistics of data recorded at Binh Dai station (S4).

\begin{tabular}{llll}
\hline Statistic Period-1 & Value & Percentile & Value \\
\hline Sample size & 10,950 & Min & 0 \\
Range & 187.3 & $5 \%$ & 0 \\
Mean & 3.942 & $10 \%$ & 0 \\
Variance & 128.8 & $25 \%$ Q1 & 0 \\
Std. deviation & 11.35 & $50 \%$ Median & 0 \\
Coef. of variation & 2.879 & $75 \%$ Q3 & 1 \\
Std. error & 0.109 & $90 \%$ & 12.69 \\
Skewness & 5.106 & $95 \%$ & 23.8 \\
Excess kurtosis & 37.12 & Max & 187.3 \\
\hline
\end{tabular}

* Period 1: 1983-2012.

Table 11 Descriptive statistics of data recorded at Binh Dai station (S4).

\begin{tabular}{llll}
\hline Statistic Period-2 & Value & Percentile & Value \\
\hline Sample size & 5,475 & Min & 0 \\
Range & 133.6 & $5 \%$ & 0 \\
Mean & 3.576 & $10 \%$ & 0 \\
Variance & 115.4 & $25 \%$ Q1 & 0 \\
Std. deviation & 10.74 & $50 \%$ Median & 0 \\
Coef. of variation & 3.004 & $75 \%$ Q3 & 0 \\
Std. error & 0.145 & $90 \%$ & 11.6 \\
Skewness & 5.07 & $95 \%$ & 22.62 \\
Excess kurtosis & 34.65 & Max & 133.6 \\
\hline
\end{tabular}

* Period 2: 1983-1997.

Table 12 Descriptive statistics of data recorded at Binh Dai station (S4).

\begin{tabular}{llll}
\hline Statistic Period-3 & Value & Percentile & Value \\
\hline Sample size & 5,475 & Min & 0 \\
Range & 187.3 & $5 \%$ & 0 \\
Mean & 4.308 & $10 \%$ & 0 \\
Variance & 141.9 & $25 \%$ Q1 & 0 \\
Std. deviation & 11.92 & $50 \%$ Median & 0 \\
Coef. of variation & 2.766 & $75 \%$ Q3 & 2 \\
Std. error & 0.161 & $90 \%$ & 13.9 \\
Skewness & 5.095 & $95 \%$ & 24.64 \\
Excess kurtosis & 38.03 & Max & 187.3 \\
\hline
\end{tabular}

* Period 3: 1998-2012. 
Table 13 Descriptive statistics of data recorded at Ben Trai station (S5).

\begin{tabular}{llll}
\hline Statistic Period-1 & Value & Percentile & Value \\
\hline Sample size & 10,950 & Min & 0 \\
Range & 219 & $5 \%$ & 0 \\
Mean & 3.975 & $10 \%$ & 0 \\
Variance & 133.1 & $25 \%$ Q1 & 0 \\
Std. deviation & 11.54 & $50 \%$ Median & 0 \\
Coef. of variation & 2.903 & $75 \%$ Q3 & 1.1 \\
Std. error & 0.11 & $90 \%$ & 13 \\
Skewness & 5.342 & $95 \%$ & 24.645 \\
Excess kurtosis & 43.76 & Max & 219 \\
\hline
\end{tabular}

* Period 1: 1983-2012.

Table 14 Descriptive statistics of data recorded at Ben Trai station (S5).

\begin{tabular}{llll}
\hline Statistic Period-2 & Value & Percentile & Value \\
\hline Sample size & 5,475 & Min & 0 \\
Range & 136.3 & $5 \%$ & 0 \\
Mean & 3.561 & $10 \%$ & 0 \\
Variance & 107.8 & $25 \% \mathrm{Q} 1$ & 0 \\
Std. deviation & 10.38 & $50 \%$ Median & 0 \\
Coef. of variation & 2.916 & $75 \%$ Q3 & 0.5 \\
Std. error & 0.14 & $90 \%$ & 11.3 \\
Skewness & 4.808 & $95 \%$ & 22.72 \\
Excess kurtosis & 31.18 & Max & 136.3 \\
\hline
\end{tabular}

* Period 2: 1983-1997.

Table 15 Descriptive statistics of data recorded at Ben Trai station (S5).

\begin{tabular}{llll}
\hline Statistic Period-3 & Value & Percentile & Value \\
\hline Sample size & 5,475 & Min & 0 \\
Range & 219 & $5 \%$ & 0 \\
Mean & 4.388 & $10 \%$ & 0 \\
Variance & 158.1 & $25 \%$ Q1 & 0 \\
Std. deviation & 12.57 & $50 \%$ Median & 0 \\
Coef. of variation & 2.865 & $75 \%$ Q3 & 1.9 \\
Std. error & 0.17 & $90 \%$ & 14.44 \\
Skewness & 5.517 & $95 \%$ & 26.5 \\
Excess kurtosis & 47.06 & Max & 219 \\
\hline
\end{tabular}

* Period 3: 1998-2012.

The first period (1983-2012) with 10,950 samples at two S1 and S2 station, sign (Z) factor are also positive (index for a creased trend). That means existing the trend in two stations above with the level of significance more than 0.95 . There is no trend in other stations (S3, S4, S5) because $\mathrm{f}(\mathrm{z})$ values are less than 0.95 (Table 16).

The second period (1983-1997) the number of sample is 5,475 but all $\mathrm{f}(\mathrm{z})$ values are less than 0.95 . Therefore, there is also no trend in all stations in this period (Table 17).

The third period (1998-2012), the number of samle is 5,475 , there is no trend in three stations ( $\mathrm{S} 3, \mathrm{~S} 4, \mathrm{~S} 5)$ because $\mathrm{f}(\mathrm{z})$ values of them are also less than 0.95 . Existing the trend in two stations (S1 and S2) and these are the positive trends (sign $(\mathrm{Z})$ factors having positive values, index for a creased trend) (Table 18).

\subsection{Frequency Magnitude of Extreme Rainfall}

With respect to the definitive period of $\mathrm{N}$ (year) (or F), it could be calculated $X_{0}$ (the value exceeds $X$ determinant value). It means that, if $X_{0}$, calculation of $\mathrm{n}$ can be made (this helps to confirm that after many years, $X$ value would have occurred over the threshold $\left.X_{01}, X_{02}, X_{03} \ldots\right)$. On the other hand, the authors can do the same procedure for the extreme values. However, the increase of $\mathrm{n}$ goes with the increase of $X$ value, and this increasing is limited.

The calculated results show that: the tends of rainfall on the maximum value within 5 years with value of $17.58 \mathrm{~mm}$ can occur by probability $20 \%$, the maximum threshold may be reached $26.65 \mathrm{~mm}$ during

Table 16 The trend of extreme rainfall in period-1.

\begin{tabular}{llllll}
\hline Station & S1 & S2 & S3 & S4 & S5 \\
\hline Sign $(Z)$ & + & + & - & - & - \\
$\mathrm{f}(\mathrm{Z})$ & $\mathbf{0 . 9 7}$ & $\mathbf{0 . 9 5}$ & 0.91 & 0.85 & 0.87 \\
\hline
\end{tabular}

Table 17 The trend of extreme rainfall in period-2.

\begin{tabular}{llllll}
\hline Station & S1 & S2 & S3 & S4 & S5 \\
\hline Sign $(\mathrm{Z})$ & + & + & - & + & - \\
$\mathrm{f}(\mathrm{Z})$ & 0.92 & 0.73 & 0.92 & 0.67 & 0.36 \\
\hline
\end{tabular}

Table 18 The trend of extreme rainfall in period-3.

\begin{tabular}{llllll}
\hline Station & S1 & S2 & S3 & S4 & S5 \\
\hline Sign $(\mathrm{Z})$ & + & + & + & - & - \\
$\mathrm{f}(\mathrm{Z})$ & $\mathbf{0 . 9 8}$ & $\mathbf{0 . 9 6}$ & 0.87 & 0.38 & 0.40 \\
\hline
\end{tabular}


Table 19 Results of the return period based on GEV distribution at 5 stations.

\begin{tabular}{|c|c|c|c|c|c|c|}
\hline \multicolumn{7}{|c|}{ Gen. extreme value ( $\mathrm{mm} /$ day) } \\
\hline Year & $\mathbf{P}^{*}$ & S1 & $\mathbf{S 2}$ & S3 & S4 & S5 \\
\hline 2 & 0.500 & 3.9 & 2.4 & 1.9 & 2.1 & 2.1 \\
\hline 3 & 0.333 & 10.4 & 7.4 & 6.4 & 6.8 & 6.9 \\
\hline 4 & 0.250 & 14.5 & 10.5 & 9.2 & 9.9 & 10.0 \\
\hline 5 & 0.200 & 17.6 & 12.9 & 11.4 & 12.1 & 12.3 \\
\hline 6 & 0.167 & 20.0 & 14.7 & 13.0 & 13.9 & 14.1 \\
\hline 7 & 0.143 & 22.1 & 16.3 & 14.4 & 15.4 & 15.6 \\
\hline 8 & 0.125 & 23.8 & 17.6 & 15.6 & 16.7 & 16.9 \\
\hline 9 & 0.111 & 25.3 & 18.8 & 16.7 & 17.8 & 18.0 \\
\hline 10 & 0.100 & 26.7 & 19.8 & 17.6 & 18.8 & 19.0 \\
\hline 15 & 0.067 & 31.8 & 23.7 & 21.1 & 22.5 & 22.8 \\
\hline 20 & 0.050 & 35.4 & 26.4 & 23.6 & 25.1 & 25.5 \\
\hline 25 & 0.040 & 38.1 & 28.5 & 25.5 & 27.2 & 27.6 \\
\hline 30 & 0.033 & 40.4 & 30.2 & 27.1 & 28.8 & 29.2 \\
\hline 35 & 0.029 & 42.3 & 31.7 & 28.4 & 30.2 & 30.6 \\
\hline 40 & 0.025 & 43.9 & 32.9 & 29.5 & 31.4 & 31.9 \\
\hline 45 & 0.022 & 45.3 & 34.0 & 30.5 & 32.4 & 32.9 \\
\hline 50 & 0.020 & 46.6 & 35.0 & 31.4 & 33.4 & 33.9 \\
\hline 55 & 0.018 & 47.8 & 35.9 & 32.2 & 34.2 & 34.8 \\
\hline 60 & 0.017 & 48.8 & 36.7 & 32.9 & 35.0 & 35.6 \\
\hline 65 & 0.015 & 49.8 & 37.4 & 33.6 & 35.7 & 36.3 \\
\hline 70 & 0.014 & 50.7 & 38.1 & 34.2 & 36.4 & 37.0 \\
\hline 75 & 0.013 & 51.6 & 38.8 & 34.8 & 37.0 & 37.6 \\
\hline 80 & 0.013 & 52.3 & 39.4 & 35.3 & 37.6 & 38.2 \\
\hline 85 & 0.012 & 53.1 & 39.9 & 35.8 & 38.1 & 38.7 \\
\hline 95 & 0.011 & 54.4 & 41.0 & 36.8 & 39.1 & 39.7 \\
\hline 100 & 0.010 & 55.1 & 41.4 & 37.2 & 39.6 & 40.2 \\
\hline
\end{tabular}

*Probability density function $\left(\mathrm{P}^{*}\right)$.

10 years by probability 0.1 . Probability of this event can be reducing to $0.05,0.03,0.02$ and 0.01 in 20 years, 30 years, 50 years and 100 years later and the peaks of rainfall thresholds are $35.35 \mathrm{~mm}, 40.35 \mathrm{~mm}$, $46.61 \mathrm{~mm}$ and $50.1 \mathrm{~mm}$, respectively (Table 19, Fig $3)$.

\subsection{Partial Duration Series in MEKONG River Delta}

Another approach is to assemble the largest values regardless of their year of occurrence. This approach is generally known as peaks-over-threshold (POT) or partial-duration data. The POT approach and its associated Generalized Pareto (GP) model are sound. Selecting a proper threshold is most critical in POT.

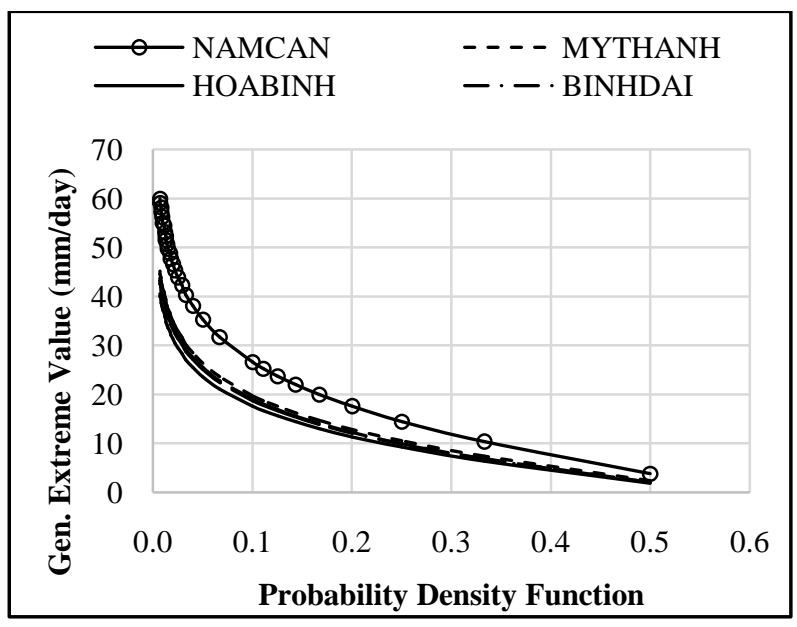

Fig. 3 Probability density function at 5 stations in MEKONG river delta.

The POT time series over the annual 90th percentile has been considered and analyzed. The exceedances or partial duration (PD) series approach were adopted and Generalized Pareto (GP) model was fitted to the resulting series to estimate the recurrence interval (1 in 5, 10, 25 and 50 years). The results of the analysis are presented in Table 20 and the calculated parameters are given in Table 21. The highest variation of extreme rainfall at $\mathrm{S} 1$ station: About 52.3 $\mathrm{mm}$ rainfall is expected to occurence in 50 years and $58.1 \mathrm{~mm}$ for the return period in 100 years. The lowest variation of extreme rainfall at S5 station: About 34.2 $\mathrm{mm}$ rainfall is expected to occurence in 50 years and $41.8 \mathrm{~mm}$ for the return period in 100 years. The average for 5 stations: about $38.96 \mathrm{~mm}$ for the period of 50 years and $46.2 \mathrm{~mm}$ for the period of 100 years.

\section{Conclusions}

Extreme precipitation event is one of the most Table 20 Estimation of return periods based on Generalized Pareto (GP) model

\begin{tabular}{lllllll}
\hline \multicolumn{7}{c}{ Gen. pareto value $(\mathbf{m m} /$ day $)$} \\
\hline Year & P* & S1 & S2 & S3 & S4 & S5 \\
\hline 02 & 0.500 & 3.86 & 2.62 & 1.93 & 2.11 & 2.05 \\
05 & 0.333 & 16.4 & 13.1 & 12.0 & 12.7 & 14.1 \\
25 & 0.250 & 40.2 & 29.3 & 28.7 & 28.6 & 27.8 \\
50 & 0.200 & 52.3 & 38.2 & 35.4 & 34.7 & 34.2 \\
100 & 0.167 & 58.1 & 45.4 & 43.6 & 42.1 & 41.8 \\
\hline
\end{tabular}


Table 21 Parameters of General Pareto distribution fitted to Partial Duration Series (POT $>90 \%$ )

\begin{tabular}{|c|c|c|c|}
\hline $\begin{array}{r}\text { No parameters } \\
k=0.66398\end{array}$ & $\begin{array}{l}\text { Kolmogorov } \\
\text { smirnov }\end{array}$ & $\begin{array}{l}\text { Anderson } \\
\text { darling }\end{array}$ & $\begin{array}{l}\text { Chi } \\
\text { squared }\end{array}$ \\
\hline $\begin{aligned} \mathrm{S} 1 \quad \sigma & =2.4371 \\
\mu & =-0.82841 \\
\mathrm{k} & =0.72243\end{aligned}$ & 0.38771 & $1,639.6$ & $7,871.8$ \\
\hline $\begin{aligned} \mathrm{S} 2 \sigma & =1.3496 \\
\mu & =-0.4883 \\
\mathrm{k} & =0.75525\end{aligned}$ & 0.43242 & $2,006.7$ & $9,443.2$ \\
\hline $\begin{aligned} \text { S3 } \sigma & =0.98891 \\
\mu & =-0.36977 \\
\mathrm{k} & =0.74833\end{aligned}$ & 0.46926 & $2,281.6$ & $11,004.0$ \\
\hline $\begin{aligned} \text { S4 } \sigma & =1.094 \\
\mu & =-0.40475 \\
\mathrm{k} & =0.75079\end{aligned}$ & 0.44192 & $2,067.0$ & $9,745.9$ \\
\hline $\begin{aligned} \text { S5 } \sigma & =1.0913 \\
\mu & =-0.40463\end{aligned}$ & 0.43817 & $2,038.7$ & $9,626.5$ \\
\hline
\end{tabular}

recurrences at 5 stations in MEKONG river delta. In this study, the daily rainfall data measured at 5 stations for 30 years were analyzed and the recurrence interval of extreme events was calculated by using various probability distributions. Analytical results show that the extreme rainfalls (95th percentile) are about $37.4 \mathrm{~mm} /$ day at $\mathrm{S} 1$ station, $27 \mathrm{~mm} /$ day at $\mathrm{S} 2$ station, $22.4 \mathrm{~mm} /$ day at $\mathrm{S} 3$ station, $23.8 \mathrm{~mm} /$ day at $\mathrm{S} 4$ station and $24.6 \mathrm{~mm} /$ day at $\mathrm{S} 5$ station, respectively. The highest rainfalls ever were $246.4 \mathrm{~mm} /$ day at $\mathrm{S} 1$, $174.5 \mathrm{~mm} /$ day at $\mathrm{S} 2,179 \mathrm{~mm} /$ day at $\mathrm{S} 3,187 \mathrm{~mm} /$ day at $\mathrm{S} 4$ and $219 \mathrm{~mm} /$ day at $\mathrm{S} 5$. The Mann-Kendall tests indicated that there were significant creasing trends of rainfall at S1 station and S2 station during the first period and the third period with probability about 95-98\%. Whereas, there was no statistically significant trends of rainfall at other stations. In order to estimate the return period of extreme rainfall events, the GEV distributions were used to calculate frequency distribution. The magnitudes of daily maximum rainfall were from 2 to 100 years. The results of return period show that maximum rainfalls of 50 years are $46.6 \mathrm{~mm}$ at $\mathrm{S} 1$ station (the highest) and $31.4 \mathrm{~mm}$ at $\mathrm{S} 3$ station (the lowest). Similarly, maximum rainfalls are expected to be for 100 years about $55.1 \mathrm{~mm}$ at $\mathrm{S} 1$ and $37.2 \mathrm{~mm}$ at $\mathrm{S} 3$.

\section{Acknowledgments}

This work was financed by the science and technological cooperation programme between the Vietnam and USA (2013-2015), the project "Interaction between hydrodynamic process Bien Dong (East Sea) and water Mekong River." It benefited also from the support given by VAST.DLT.06/15-16 project.

\section{References}

[1] Mann HB. 1945. "Nonparametric Tests against Trend." Econometrica 13 (3): 245-259.

[2] Kendall, M.G. 1975. Rank Correlation Methods. edited by Charles Griffin. London: Charles Griffin\& Co. Ltd.

[3] Hirsch R. M., Slack J. R., and Smith R. A. 1982. "Techniques of Trend Analysis for Monthly Water Quality Data." Water Resources Research 18 (1): 107-121.

[4] Lettenmaier D. P., Wood E. F., and Wallis J. R. 1994. "Hydro-climatological Trends in the Continental United States." Journal of Climate 7: 586-607.

[5] Burn, D. H., and Hag-Elnur M. A. 2002. "Detection of Hydrologic Trend and Variability." Journal of Hydrology 255: 107-122.

[6] Jenkinson A. F. 1955. "The Frequency Distribution of the Annual Maxima (or Minima) Values of Meteorological Elements." Quarterly Journal of the Royal Meteorological Society 81: 158-171.

[7] Hosking J. R. M., Wallis J. R., and Wood E. F. 1985. "Estimation of the Generalized Extreme Value Distribution by the Method of Probability Weighted Moments." Technometrics 27: 251-261.

[8] Galambos J. 1987. The Asymptotic Theory of Extreme Order Statistics, 2nd edn. Melbourne: Publishing Co. Inc.. 